\title{
Visualization of Cavity Regions by Hammering Test Using the Level Set Type Topology Optimization Based on the Concept of the Phase Field Method
}

by

\author{
Kenta YoShiHARA*, Takahiko KURAHASHI ${ }^{* *}$, Yuki MURAKAMI ${ }^{* * *}$, Shigehiro TOYAMA ${ }^{* * * *}$, \\ Fujio IKEDA ${ }^{* * * * *}$, Tetsuro IYAMA ${ }^{* * * * *}$ and Ikuo IHARA*
}

\begin{abstract}
This paper describes a visualization of cavity regions in a structure by a hammering test using the level set type topology optimization based on the concept of the phase field method. In this study, the residual between the calculated displacement and the observed displacement was defined as the performance function, and the identification problem of cavity regions was formulated based on the adjoint variable and finite element methods. The numerical experiments were performed to investigate the effect of the regularization parameter. According to this result, it was found that the number of cavities and the cavity shape were affected the regularization parameter. In addition, the numerical example of a three-dimensional problem was described.
\end{abstract}

Key words:

Topology optimization, Level set method, Phase field method, Shape identification,

Adjoint variable method, Finite element method, hammering test.

\section{1 序論}

近年，橋梁などの土木構造物の老朽化が深刻となって いる. 2012 年に発生した笹子トンネル天井板落下事故 を契機に,インフラ点検に対する重要度が見直された。 非破壊で構造内部の欠陥を検查する方法として，打音試 験 1) や打撃試験 2),3) というものがある. 構造物をハン マーで打撃することは共通しているが, 構造内部の欠陥 を評価する際に，空間に伝搬する音を用いる方法を打音 試験, 構造物表面の振動を用いる方法を打撃試験と区別 している. 簡便な方法であるため, 道路橋やトンネル等 の定期点検では広く用いられている. 既往の研究では, 打音試験や打撃試験によって得られた波形データを分析 し，マッピングすることや，機械学習を利用することで 構造内部の空洞を可視化する試みがされている ${ }^{4)}$ 。これ らの方法では, 構造物表面を格子状に打撃する必要があ り, 空洞領域を定量的に評価するためには試験回数が多 くなる.

本研究では, トポロジー最適化 ${ }^{5)}$ の手法に基づいて, 打撃試験に扔ける空洞領域の可視化法について数值実験 を行う. トポロジー最適化は, 外形形状に加え, 空洞の

\begin{abstract}
数を最適化する構造最適化手法であり, 一度の打撃試験 データから逐次計算によって空洞領域を同定するため, 構造内の空洞領域を視覚的に評価することや, 打撃試 験回数の削減が期待できる. トポロジー最適化の中でも 様々なタイプが存在するが, 物体と空洞を明確に判別す るために, 本研究ではレベルセット型トポロジー最適化 6) に着目する. 非破壊検査とレベルセット法に基づくト ポロジー最適化は, 境界要素法とトポロジカル・デリバ ティブ7)を用いた方法によって検討されている ${ }^{8)}$. 境界 要素法は物体領域内部に対して要素分割を行わないた め, 計算コストの削減が期待できるが, 物体領域内部に 空洞が生成された場合, 空洞境界に対して要素分割を逐 次行う必要がある.トポロジカル・デリバティブとは, 物体領域から空洞領域の創出を行う感度である. レベル セット型トポロジー最適化は, 物体領域から空洞領域の ように離散的に変化する最適化問題を, レベルセット関 数の正負によって領域を表す連続な関数を導入し, レベ ルセット関数の最適化問題を解くことで構造最適化が行 われるものである.トポロジカル・デリバティブは, こ のレベルセット関数を変化させるために用いられるが,
\end{abstract}

$\dagger$ 原稿受理 令和 2 年 1 月 22 日 Received Jan. 22, 2020 C2021 The Society of Materials Science, Japan

* 長岡技術科学大学大学院 機械創造工学専攻 † 940-2188 長岡市上富岡町

Dept. of Mechanical Engineering, Nagaoka University of Technology, Kamitomioka-cho, Nagaoka, 940-2188.

* 正会員 長岡技術科学大学大学院 機械創造工学専攻 ₹ 940-2188 長岡市上富岡町

Dept. of Mechanical Engineering, Nagaoka University of Technology, Kamitomioka-cho, Nagaoka, 940-2188.

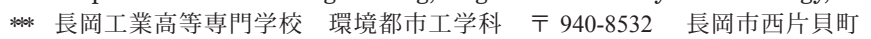

Dept. of Civil Engineering, National Institute of Technology, Nagaoka College, Nishikatakai-cho, Nagaoka, $940-8532$.

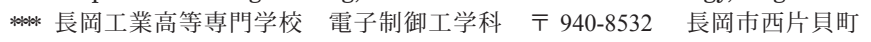

Dept. of Electrical \& Electronic Systems Engineering, National Institute of Technology, Nagaoka College, Nishikatakai-cho, Nagaoka, $940-8532$.

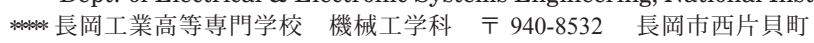

Dept. of Mechanical Engineering, National Institute of Technology, Nagaoka College, Nishikatakai-cho, Nagaoka, $940-8532$. 
どの程度のトポロジカル・デリバティブの值の場所に空 洞領域を創出するかということに対して議論がある ${ }^{9)}$. そこで, 本論文では, 打撃試験による空洞領域同定問題 を Yamada らが提案した, フェーズフィールド法の考え 方に基づいたレベルセット型トポロジー最適化理論 ${ }^{10)}$ により定式化する。この方法では，レベルセット関数に 対し 1 と -1 の上限值・下限值を設け, トポロジカル・デ リバティブを駆動力とした反応拡散モデルによってレベ ルセット関数の更新が行われる. 本論文では, 2 次元と 3 次元の空洞領域同定問題に対して定式化を行い, 数值 実験により妥当性を確認する.

\section{2 フェーズフィールド法の考え方に基づくトポロジー 最適化}

フェーズフィールド法は，凝固現象や二相以上の流れ 場を数值解析する時に多く用いられる方法である ${ }^{11)}$. 例 えば，凝固現象では，状態をフェーズフィールド恋数 $\phi$ によって定義し, 固相ならば $\phi=1$, 液相ならば $\phi=0$, 固相と液相の界面は 0 から 1 へ急峻に変化するように与

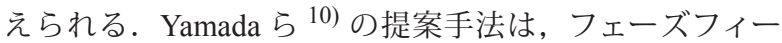
ルド法の考え方をレベルセット型トポロジー最適化に応 用し, 界面移動と空洞領域の創成を可能にした構造最適 化手法となっている.

まず，抽象的な構造最適化問題に対するトポロジー最 適化の定式化を行う。物体により占められている領域 $\Omega$ （以下，物体領域）と，物体領域 $\Omega$ を内包する固定設計 領域 $D$ における, 物体領域の構造最適化問題を考える. ここで, 物体領域 $\Omega$ はレベルセット関数 $\phi$ の值に応じて 可変であり, 固定領域 $D$ は最適化計算過程において常に 一定の領域である．レベルセット法では，レベルセット 関数 $\phi(\boldsymbol{x})$ の正負によって領域を区別し，レベルセット関 数が正ならば物体領域，負ならば空洞領域，0ならば物 体の境界としている。これを数式で表現すると, 式 (1) で表される。

$$
\phi(\boldsymbol{x})= \begin{cases}0<\phi(\boldsymbol{x}) \leq 1 & \text { in } \Omega \\ \phi(\boldsymbol{x})=0 & \text { on } \partial \Omega \\ -1 \leq \phi(\boldsymbol{x})<0 & \text { in } D-\Omega\end{cases}
$$

ここで， $\partial \Omega$ は物体の境界を表すレベルセット法による 構造最適化問題は, 目的汎関数（ラグランジュ関数） $F$ が最小となるレベルセット関数 $\phi$ の分布を求める問題に 帰着するため, 式 (2) のように定義することができる.

$$
F(\Omega(\phi))=\int_{\Omega} f(\boldsymbol{x}) d \Omega \rightarrow \min
$$

ここで, $f(\boldsymbol{x})$ はラグランジュ関数の物体領域に対する被 積分関数である.フェーズフィールド法の考え方に基づ いた方法では, 界面エネルギーを目的汎関数に加え, 式 (3)のように設計空間の緩和を行う.

$$
F(\Omega(\phi), \phi)=\int_{\Omega} f(\boldsymbol{x}) d \Omega+\int_{D} \frac{1}{2} \tau|\nabla \phi|^{2} \rightarrow \min
$$

上式は，チコノフの正則化法 ${ }^{12), 9)}$ に基づいた正則化と 同等であるため，本論文では式 (3) の右辺第 2 項を正則
化項， $\tau$ を正則化パラメータと呼ぶことにする. フェー ズフィールド法の考え方に基づき, 構造最適化問題をレ ベルセット関数 $\phi$ の時間発展問題に置き換えると式 (4) のように表すことができる。

$$
\frac{\partial \phi}{\partial \tilde{t}}=-K(\phi) \frac{\delta F}{\delta \phi}
$$

ここで, $K(\phi)$ は正のパラメータ, $\tilde{t}$ は最適化方向を表す 仮想的な時間である。また, $\delta F / \delta \phi$ は目的汎関数 $F$ のレ ベルセット関数 $\phi$ に対する汎関数微分を意味する. 上式 に式(3)を代入すると，式(5)が得られる.

$$
\left\{\begin{array}{l}
\frac{\partial \phi}{\partial \tilde{t}}=-K(\phi)\left[C f(\boldsymbol{x}) H(\phi)-\tau \nabla^{2} \phi\right] \\
\frac{\partial \phi}{\partial n}=0 \text { on } \partial D-\partial D_{N . D .} \\
\phi=1 \text { on } \partial D_{N . D .}
\end{array}\right.
$$

ここで, $H(\phi)$ は物体領域で 1 , 空洞領域で 0 となるへビ サイド関数, $C$ は正のパラメータである. また, ラグラ ンジュ関数の物体領域に対する被積分関数 $f(\boldsymbol{x})$ が, レベ ルセット関数 $\phi$ を更新させるためのラグランジュ関数の 感度，すなわちトポロジカル・デリバティブに相当する.

\section{3 空洞領域同定問題の定式化}

本論文では, 打撃試験により測定される観測変位と数 值解析によって得られる変位を用いて空洞形状の評価を 行う式を作成する．測定される変位べクトル $\boldsymbol{u}_{o b s}$ と数 值計算によって得られる変位べクトル $\boldsymbol{u}$ との差の二乗積 分值を評価関数として式(6)により定義する.

$$
J=\frac{1}{2} \int_{T} \int_{\Omega}\left(\boldsymbol{u}-\boldsymbol{u}_{o b s}\right)^{T} \boldsymbol{Q}\left(\boldsymbol{u}-\boldsymbol{u}_{o b s}\right) d \Omega d t
$$

ここで, $\boldsymbol{Q}$ は重み対角行列であり, 観測変位 $\boldsymbol{u}_{o b s}$ の成 分が 0 ならば対応する $\boldsymbol{Q}$ の成分も 0 , それ以外の対角成 分は 0 より大きい值である. 打撃試験を数值シミュレー ションするために, 非定常問題における等方性線形弾性 体の平衡方程式, 応力とひずみの関係式, ひずみと変位 の関係式をそれぞれ式 (7)〜式 (10) に示す。また，境界 条件および初期条件をそれぞれ式 (11)〜式 (13) に示す.

$$
\begin{gathered}
\boldsymbol{\partial}^{T}\left(\boldsymbol{\sigma}+\boldsymbol{\sigma}^{d}\right)-c_{M} \rho \dot{\boldsymbol{u}}-\rho \ddot{\boldsymbol{u}}=\mathbf{0} \\
\boldsymbol{\sigma}=\boldsymbol{D} \boldsymbol{\varepsilon} \\
\boldsymbol{\sigma}^{d}=c_{K} \boldsymbol{D} \dot{\boldsymbol{\varepsilon}} \\
\boldsymbol{\varepsilon}=\boldsymbol{\partial} \boldsymbol{u} \\
\boldsymbol{u}=\mathbf{0} \quad \text { on } \Gamma_{u} \\
\boldsymbol{n}^{T}\left(\boldsymbol{\sigma}+\boldsymbol{\sigma}^{d}\right)=\hat{\boldsymbol{p}} \text { on } \Gamma_{\sigma} \\
\boldsymbol{u}=\mathbf{0} \text { in } \Omega, T=t_{0}
\end{gathered}
$$

ここで, $\sigma$ は応力べクトル,$\varepsilon$ はひずみべクトル,$\rho$ は 質量密度, $c_{M}$ は質量減衰パラメータ, $c_{K}$ は構造減衰パ ラメータ, $\boldsymbol{D}$ は弾性係数行列, $\partial$ はひずみを表現するた めの微分作用素行列, $\boldsymbol{n}$ は単位法線行列, $\Gamma_{u}$ は変位境 界, $\Gamma_{\sigma}$ は外力境界, $p$ は表面力ベクトルであり, ( ) は 時間微分, (^) は既知量, 添字 $d$ は粘性減衰を表す. 随伴 
変数ベクトル $\psi$ を導入し, 式 (14) に示すようなラグラ ンジュ関数 $F$ を定義する。

$$
\begin{aligned}
& F(\Omega(\phi)) \\
= & J(\boldsymbol{u}) \\
+ & \int_{T} \int_{\Omega} \boldsymbol{\psi}^{T}\left[\boldsymbol{\partial}^{T}\left(\boldsymbol{\sigma}+\boldsymbol{\sigma}^{d}\right)-c_{M} \rho \dot{\boldsymbol{u}}-\rho \ddot{\boldsymbol{u}}\right] d \Omega d t \\
= & \int_{\Omega} f(\boldsymbol{x}) d \Omega
\end{aligned}
$$

したがって，未知変数ベクトルである $u, \psi$ を計算する ことで被積分関数 $f(\boldsymbol{x})$ を求めることができる.上式の 第一変分と停留条件から, 弱形式化された支配方程式, 随伴方程式, 随伴変数べクトルに対する境界条件, 終端 条件がそれぞれ式 (15)〜 式 (18)のように導かれる.

$$
\begin{gathered}
-\int_{\Omega} \delta(\boldsymbol{\partial} \boldsymbol{\psi})^{T}\left(\boldsymbol{\sigma}+\boldsymbol{\sigma}^{d}\right) d \Omega-\int_{\Omega} \delta \boldsymbol{\psi}^{T} c_{M} \rho \dot{\boldsymbol{u}} d \Omega \\
-\int_{\Omega} \delta \boldsymbol{\psi}^{T} \rho \ddot{\boldsymbol{u}} d \Omega=-\int_{\Gamma_{\sigma}} \delta \boldsymbol{\psi}^{T} \boldsymbol{n}^{T}\left(\boldsymbol{\sigma}+\boldsymbol{\sigma}^{d}\right) d \Gamma \\
-\int_{\Omega} \ddot{\boldsymbol{\psi}}^{T} \rho \delta \boldsymbol{u} d \Omega+\int_{\Omega} \dot{\boldsymbol{\psi}}^{T} c_{M} \rho \delta \boldsymbol{u} d \Omega \\
+\int_{\Omega}(\boldsymbol{\partial} \dot{\boldsymbol{\psi}})^{T} c_{K} \boldsymbol{D} \delta \boldsymbol{u} d \Omega-\int_{\Omega}(\boldsymbol{\partial} \boldsymbol{\psi})^{T} \boldsymbol{D} \delta \boldsymbol{u} d \Omega \\
=\int_{\Gamma_{o b s}}\left(\boldsymbol{u}-\boldsymbol{u}_{o b s}\right)^{T} \boldsymbol{Q} \delta \boldsymbol{u} d \Gamma \\
\boldsymbol{\psi}=\mathbf{0} \quad \text { on } \quad \Gamma_{u} \\
\boldsymbol{\psi}=\mathbf{0} \quad \text { in } \quad \Omega, T=t_{f}
\end{gathered}
$$

ここで, $\delta$ は任意の変化量を意味する.

\section{4 数值解析法}

\section{$4 \cdot 1$ 計算領域の拡張}

弱形式化された支配方程式，随伴方程式の積分領域は 物体領域 $\Omega$ であり, 最適化過程で $\Omega$ が変動するため計 算が容易ではない，そこで，空洞領域で仮想的な物性值 を与え, 固定設計領域 $D$ に拡張することで, 物体形状を 陽に抽出することなく未知べクトルを解析する．固定設 計領域 $D$ に拡張された支配方程式および随伴方程式の 弱形式は，それぞれ式 (19), 式 (20)のように表される.

$$
\begin{aligned}
& -\int_{D} \delta(\boldsymbol{\partial} \boldsymbol{\psi})^{T}\left(\boldsymbol{\sigma}+\boldsymbol{\sigma}^{d}\right) \tilde{H}(\phi) d \Omega-\int_{D} \delta \boldsymbol{\psi}^{T} c_{M} \rho \dot{\boldsymbol{u}} \tilde{H}(\phi) d \Omega \\
& -\int_{D} \delta \boldsymbol{\psi}^{T} \rho \ddot{\boldsymbol{u}} \tilde{H}(\phi) d \Omega=-\int_{\Gamma_{\sigma}} \delta \boldsymbol{\psi}^{T} \boldsymbol{n}^{T}\left(\boldsymbol{\sigma}+\boldsymbol{\sigma}^{d}\right) d \Gamma \quad(19) \\
& -\int_{D} \ddot{\boldsymbol{\psi}}^{T} \rho \delta \boldsymbol{u} \tilde{H}(\phi) d \Omega+\int_{D} \dot{\boldsymbol{\psi}}^{T} c_{M} \rho \delta \boldsymbol{u} d \Omega \\
& +\int_{D}(\boldsymbol{\partial} \dot{\boldsymbol{\psi}})^{T} c_{K} \boldsymbol{D} \delta \boldsymbol{u} \tilde{H}(\phi) d \Omega-\int_{D}(\boldsymbol{\partial} \boldsymbol{\psi})^{T} \boldsymbol{D} \delta \boldsymbol{u} \tilde{H}(\phi) d \Omega \\
& =\int_{\Gamma_{o b s}}\left(\boldsymbol{u}-\boldsymbol{u}_{o b s}\right)^{T} \boldsymbol{Q} \delta \boldsymbol{u} d \Gamma
\end{aligned}
$$

ここで, $\tilde{H}(\phi)$ は式 (21) に示すような, 空洞領域で正の 微小值 $d$, 遷移幅 $w$ の区間で連続な, 近似されたへビサ
イド関数である.

$$
\tilde{H}(\phi)=\left\{\begin{array}{l}
d \quad \text { if } \phi<-w \\
\left\{\frac{1}{2}+\frac{\phi}{w}\left[\frac{15}{16}-\frac{\phi^{2}}{w^{2}}\left(\frac{5}{8}-\frac{3}{16} \frac{\phi^{2}}{w^{2}}\right)\right]\right\} \\
1-d)+d \text { if }-w \leq \phi \leq w \\
1 \quad \text { if } w<\phi
\end{array}\right.
$$

\section{$4 \cdot 2$ 支配方程式および随伴方程式の離散化}

式 (19), 式 (20) に対し, 有限要素法に基づいて空間方 向に離散化すると, それぞれ式(22), 式(23)のように表 される。

$$
\begin{aligned}
& M \ddot{U}+C \dot{U}+K \boldsymbol{U}=\boldsymbol{F} \\
& M \ddot{\Psi}-C \dot{\Psi}+K \Psi=S
\end{aligned}
$$

ここで, $M$ は質量行列, $C$ は減衰行列, $K$ は剛性行列, $U$ は節点值で構成される変位べクトル， $\Psi$ は節点值で 構成される随伴変数べクトル, $\boldsymbol{F}$ は節点值で構成される 外力ベクトル, $S$ は節点值で構成される随伴外力ベクト ルである。また，ニューマークの $\beta$ 法を用いて時間方向 に離散化すると, 空間方向と時間方向に離散化された支 配方程式および随伴方程式はそれぞれ式 (24), 式 (25) に より表される。

$$
\begin{aligned}
& \left(\boldsymbol{M}+\frac{\Delta t}{2} \boldsymbol{C}+\beta \Delta t^{2} \boldsymbol{K}\right) \ddot{\boldsymbol{U}}^{(n+1)} \\
= & \boldsymbol{F}^{(n+1)}-\boldsymbol{C}\left(\dot{\boldsymbol{U}}^{(n)}+\frac{\Delta t}{2} \ddot{\boldsymbol{U}}^{(n)}\right) \\
- & \boldsymbol{K}\left(\boldsymbol{U}^{(n)}+\Delta t \dot{\boldsymbol{U}}^{(n)}+\left(\frac{1}{2}-\beta\right) \Delta t^{2} \ddot{\boldsymbol{U}}^{(n)}\right) \\
& \left(\boldsymbol{M}+\frac{\Delta t}{2} \boldsymbol{C}+\beta \Delta t^{2} \boldsymbol{K}\right) \ddot{\boldsymbol{\Psi}}^{(n-1)} \\
= & \boldsymbol{S}^{(n-1)}-\boldsymbol{C}\left(\dot{\boldsymbol{\Psi}}^{(n)}+\frac{\Delta t}{2} \ddot{\boldsymbol{\Psi}}^{(n)}\right) \\
- & \boldsymbol{K}\left(\boldsymbol{\Psi}^{(n)}+\Delta t \dot{\boldsymbol{\Psi}}^{(n)}+\left(\frac{1}{2}-\beta\right) \Delta t^{2} \ddot{\boldsymbol{\Psi}}^{(n)}\right)
\end{aligned}
$$

ここで, $\Delta t$ は時間刻み, $\beta$ はパラメータ, 添字 $n$ は時間 ステップである.

\section{$4 \cdot 3$ レベルセット関数の時間発展方程式の離散化}

まず，式 (5)に対し，仮想的な時間方向に対して陰解 法を用いて離散化を行うと, 式(26)のように表される.

$$
\left\{\begin{array}{l}
\frac{\phi^{(k+1)}}{\Delta \tilde{t}}-K\left(\phi^{(k)}\right) \tau \nabla^{2} \phi^{(k+1)} \\
=-K\left(\phi^{(k)}\right) C f(\boldsymbol{x})^{(k)} H\left(\phi^{(k)}\right)-\frac{\phi^{(k)}}{\Delta \tilde{t}} \\
\phi=1 \text { on } \partial D_{N . D .}
\end{array}\right.
$$

ここで, $\Delta \tilde{t}$ は仮想的な時間刻み, 添字 $k$ は最適化ステッ プを表す. 次に, 上式を弱形式化し, 有限要素法に基づ いて空間方向に離散化すると式 (27) が得られる.

$$
\left\{\begin{array}{l}
\boldsymbol{T} \boldsymbol{\Phi}^{(k+1)}=\boldsymbol{Y} \\
\boldsymbol{\Phi}=\mathbf{1} \text { on } \partial \Gamma_{N . D .}
\end{array}\right.
$$

ここで， $\Phi$ は節点值で構成されるレベルセット関数べク トルである。また，係数マトリクス $T$ およびベクトル 
$\boldsymbol{Y}$ は, 形状関数ベクトル $\boldsymbol{N}$ を用いて, それぞれ式 (28), 式(29)のように表される.

$$
\begin{gathered}
\boldsymbol{T}=\sum_{e=1} \int_{V_{e}}\left[\frac{1}{\Delta \tilde{t}} \boldsymbol{N}^{T} \boldsymbol{N}+\nabla^{T} K\left(\phi^{(k)}\right) \tau \boldsymbol{\nabla} \boldsymbol{N}\right] d V_{e} \quad(28) \\
\boldsymbol{Y}=\sum_{e=1} \int_{V_{e}}\left[-K\left(\phi^{(k)}\right) C f(\boldsymbol{x})^{(k)} H\left(\phi^{(k)}\right)+\frac{\phi^{(k)}}{\Delta t}\right] \boldsymbol{N} d V_{e}
\end{gathered}
$$

なお，式(6)，(22), (23)についても，各最適化ステップ $k$ におけるレベルセット関数の解析に合わせて計算を行う.

\section{$4 \cdot 4$ 計算アルゴリズム}

本論文における空洞領域同定の計算アルゴリズムを以 下に示す. また，計算フローチャートを Fig. 1 に示す.

1. 計算メッシュ, 境界条件, 初期条件, 計算パラメー タを入力する. また, 反復計算回数 $k=0$ とする.

2. 支配方程式（式 (22)）を解いて, 評価関数 $J^{(k)}$ （式 (6)）を計算する.

3. $k>0$ のとき, 評価関数の収束判定を行う. $\mid J^{(k)}-$ $J^{(k-1)} / J^{0} \mid<\epsilon$ を満たすならば，計算を終了し，そ うでなければ次のステップに進む。

4. 随伴方程式（式 (23)）を解き，ラグランジュ関数の 領域被積分関数 $f(\boldsymbol{x})$ （式 (14)）を計算する.

5. レベルセット関数の時間発展式（式 (27)）により, レベルセット関数 $\boldsymbol{\Phi}^{(k+1)}$ を計算する.

6. レベルセット関数值に基づいて構造形態を更新し, $k=k+1$ としてステップ 2 に戻る.

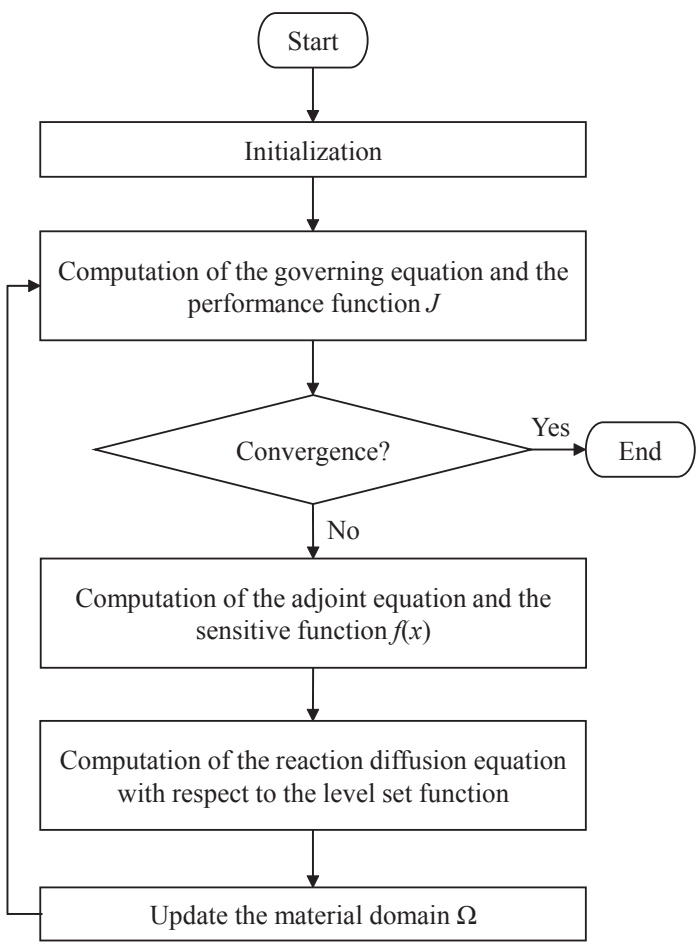

\section{5 数值実験例}

\section{$5 \cdot 12$ 次元問題による数值検証}

2 次元平面応力状態の構造物を仮定し, 空洞領域同定 シミュレーションを行う。本検討では, 固定設計領域 $D$ は横 $2.0 \mathrm{~m}$, 縦 $0.5 \mathrm{~m}$ の矩形領域を解析対象とし, 設計領 域を一辺 $1.0 \times 10^{-3} \mathrm{~m}$ （総要素数 40000 , 総節点数 40501） の四辺形一次要素で要素分割した. Fig. 2 に示すように 境界条件を設定し, 非設計領域は境界条件の影響を低減 するために与えた. 入力打撃力は式 (30) に示すガウシア ンパルスによって与え, $F_{\max }=2000 \mathrm{~N}, t_{\text {peak }}=1.0 \mathrm{~ms}$, $s=0.1 \mathrm{~ms}$ に設定した.

$$
F(t)=F_{\text {max }} \exp \left(\frac{-\left(t-t_{\text {peak }}\right)^{2}}{s^{2}}\right)
$$

正解とする空洞モデル（目標モデル）と逆解析初期の空 洞モデル（初期モデル）をそれぞれ Fig. 3, Fig. 4 に示す. ここで, 赤色は物体領域, 青色は空洞領域である. 目標 モデルは小さい矩形空洞が 2 つ存在し, 初期モデルは大 きい矩形空洞が 1 つ存在するものとして設定した.

パラメータ $K(\phi)$ や, 初期構造が最適構造に与える影 響は小さく, 正則化パラメータ $\tau$ の設定が最適構造に影響 を与えることがわかっている ${ }^{9)}$. そこで本検討では, 正則 化パラメータ $\tau$ を変化させたとき，同定計算に与える影 響を調べる.ここでは, 正則化パラメータ $\tau=1.0 \times 10^{-1}$, $1.0 \times 10^{-2}, 1.0 \times 10^{-3}$ に設定し，それぞれ”Case 1", ”Case 2”, ”Case 3”とした。本検討では，ラグランジュ関数の被 積分関数 $f(\boldsymbol{x})$ の領域平均值 $\bar{f}$ を用いて, $C=1 / \bar{f} \Delta \tilde{t}$ に 設定した。また，パラメータ $K(\phi)=\exp \left(-\phi^{2}\right)$ に設定 することで物体領域と空洞領域の界面移動を優先する。 評価関数の重み係数は, $q_{u}=0, q_{v}=1.0 \times 10^{16}$ とし, 仮想時間刻みは計算が安定するように $\Delta \tilde{t}=1.0 \times 10^{-7}$ に設定した．材料はコンクリートを想定し，計算条件を Table 1 に示す*

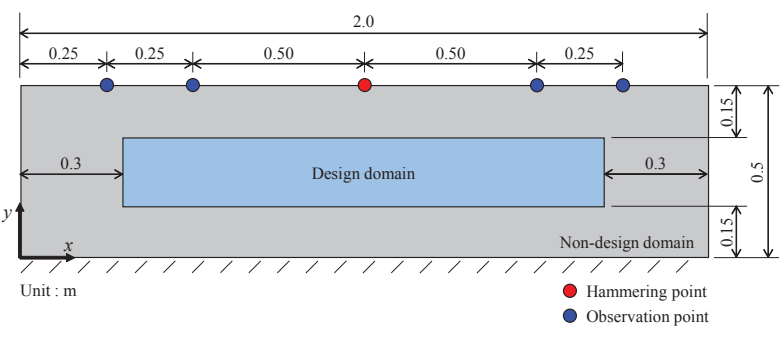

Fig. 2 Computational domain

Fig. 1 Computational flow. 


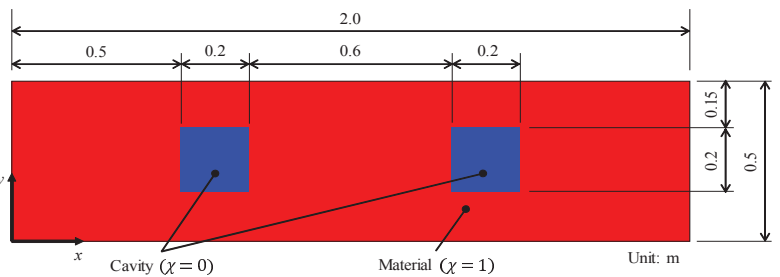

Fig. 3 Target model.

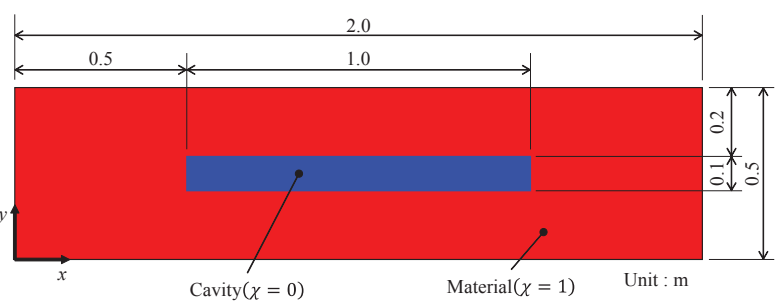

Fig. 4 Initial model

Table 1 Computational conditions.

\begin{tabular}{c|c}
\hline \hline Number of time steps & 256 \\
\hline Time increment $\Delta t, \mu \mathrm{s}$ & 39.0625 \\
\hline Time domain $T, \mathrm{~ms}$ & 10.0 \\
\hline Young's modulus $E, \mathrm{GPa}$ & 35.096 \\
\hline Poisson's ratio $\nu$ & 0.16 \\
\hline Mass density $\rho, \mathrm{kg} / \mathrm{m}^{3}$ & 2300.0 \\
\hline Damping parameter $c_{M}, c_{K}$ & $90.0,1.0 \times 10^{-6}$ \\
\hline Convergence criterion $\epsilon$ & $1.0 \times 10^{-4}$ \\
\hline
\end{tabular}

Fig. 5 Fig. 7 に Case 1 Case 3 の同定された空洞形状 を示す. Case 1 では計算領域全体が物体領域となったが, Case 2 では空洞領域が 2 個に増加し, Case 3 では空洞 領域の数は変化しなかった。 また, Case 2 と Case 3 の空 洞領域の下部について比較すると, Case 2 では滑らかに 丸みを帯びているが，Case 3 では初期構造と同じように 平坦となっている。これは, 空洞下部では変位や随伴変 数が伝達しにくいため，ラグランジュ関数の感度となる $f(\boldsymbol{x})$ の值が小さくなる。一方で, 正則化項の大きさは, 物体と空洞の界面拡散の度合を表し, 正則化パラメータ $\tau$ によって調整される。したがって, 正則化パラメータ $\tau$ を大きくすることで空洞領域の表面形状が大きく変化 するものと考えられる. Fig. 8 に評価関数の収束履歴を 示す。評価関数が上昇する部分があるが，おおむね減少 し続け，特に Case 2 の収束值は初期状態よりも大幅に減 少している. また, 評価関数の各反復回数における変化 は Case 1>Case $2>$ Case3 となっている．これは，正則化 パラメータ $\tau$ が大きいほど，式 (3) のラグランジュ関数 $F(\Omega(\phi), \phi)$ のレベルセット関数 $\phi$ に対する変化が大きく なるためである。

理想としては、同定後の空洞形状が目標とする空洞形 状と完全に一致することであるが，正則化パラメータ $\tau$ の設定により同定後の空洞形状が変わることも事実であ る.現場への適用を考える際には, 実際の打撃試験にお
いて適切な正則化パラメータ $\tau$ の設定に関する検討を実 施することにより, 従来の打撃試験に比べ修繥箇所を適 切に把握できると考えている.

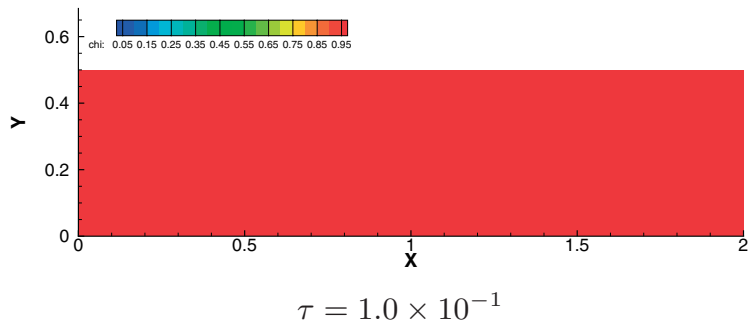

Fig. 5 Identified result in Case 1.

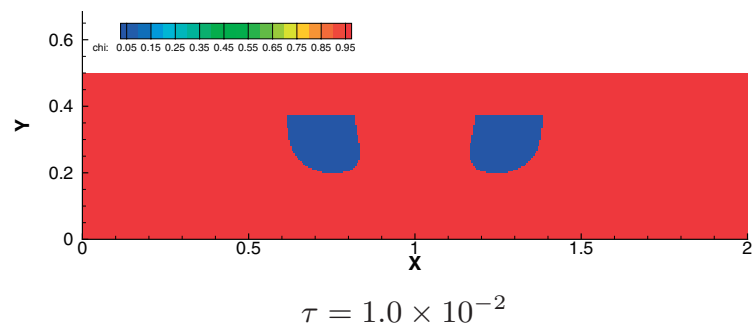

Fig. 6 Identified result in Case 2.

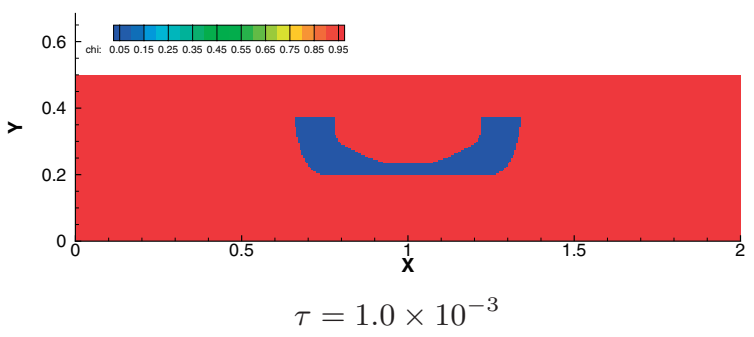

Fig. 7 Identified result in Case 3 .

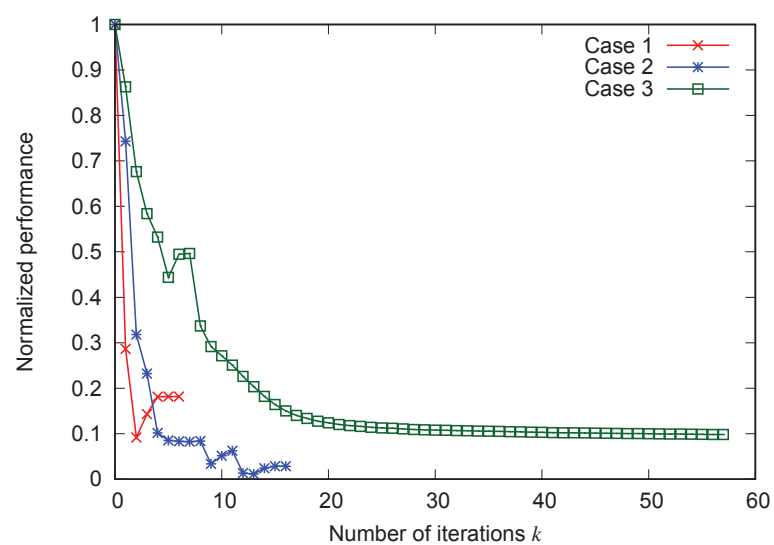

Fig. 8 Convergence history of the performance function. 

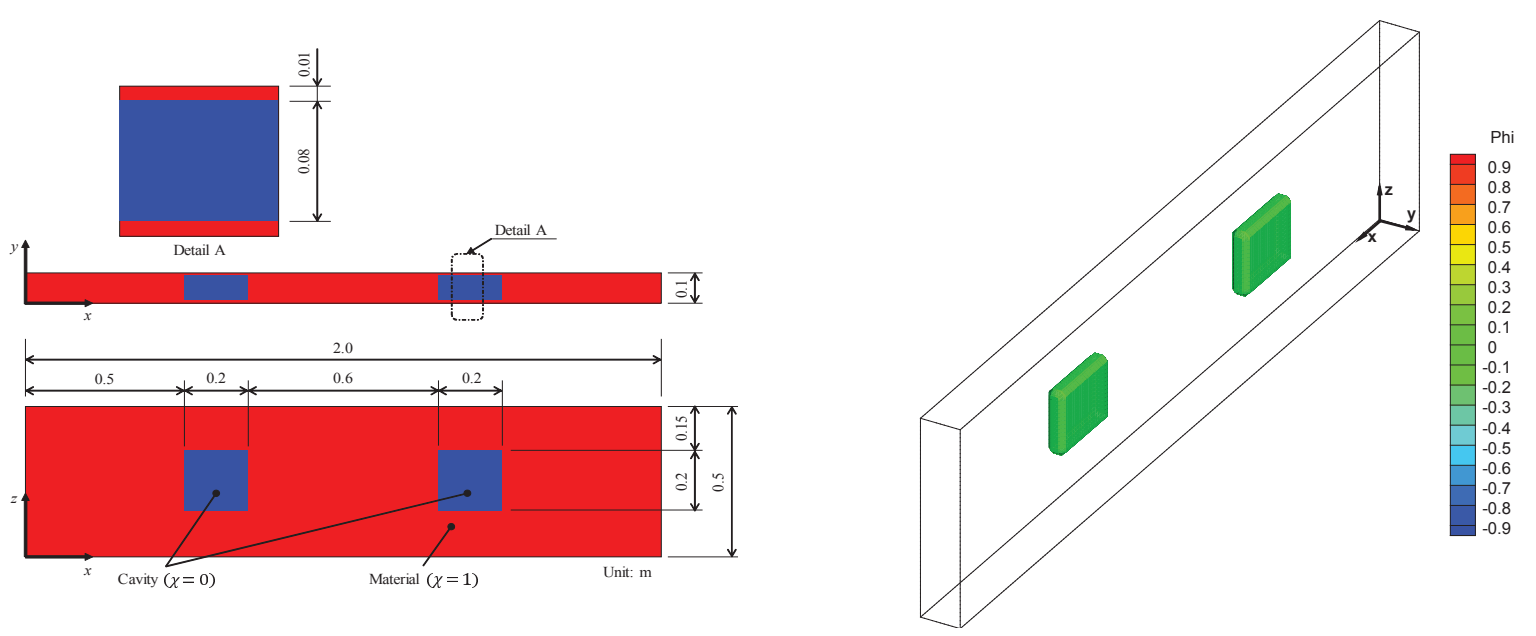

Fig. 9 Target model.
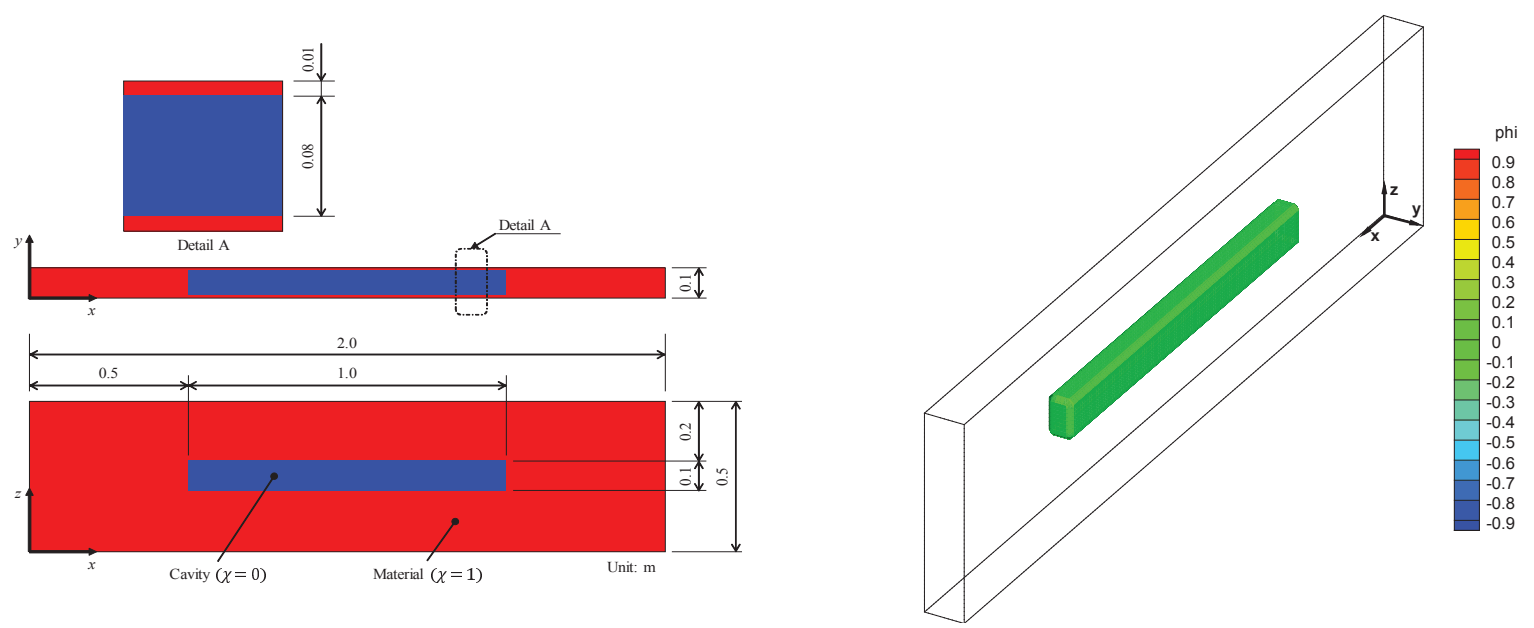

Fig. 10 Initial model.

\section{$5 \cdot 23$ 次元問題の適用例}

前節を 3 次元に拡張したモデルを想定し, Fig. 9, Fig. 10 にそれぞれ，目標モデルおよび初期モデルを示す。本 検討では, 内部空洞を可視化するために, レベルセット 関数值 $\phi=0$ の等值面をコンター図に描画し, 物体領域 と空洞領域の境界面を表すことにした。計算領域は， $x$ 方向 $2.0 \mathrm{~m}, y$ 方向 $0.1 \mathrm{~m}, z$ 方向 $0.5 \mathrm{~m}$ の直方体とし, 一辺 $10 \mathrm{~mm}$ （総要素数 100000 , 総節点数 112761）の六面体一 次要素によって要素分割した。境界条件は Fig. 11 のよう に設定し，観測点 $\mathrm{P} 1 \sim \mathrm{P} 4$ における観測変位は $z$ 方向の み使用し，入力打撃力は前節と同様に $z$ 方向下向きに与 えた。 また，変位拘束条件は下面を完全固定として与え た. 本検討では, 定数 $C=1 / \bar{f} \Delta \tilde{t}$, パラメータ $K(\phi)=1$ （一定）とした。 また, 評価関数の重み係数は, $q_{u}=0$, $q_{v}=0, q_{w}=1.0 \times 10^{16}$ とし, 仮想時間刻みは計算が安 定になるように $\Delta \tilde{t}=1.0 \times 10^{-8}$ に設定した．その他計 算条件は 5.1 節の Table 1 と同様である.

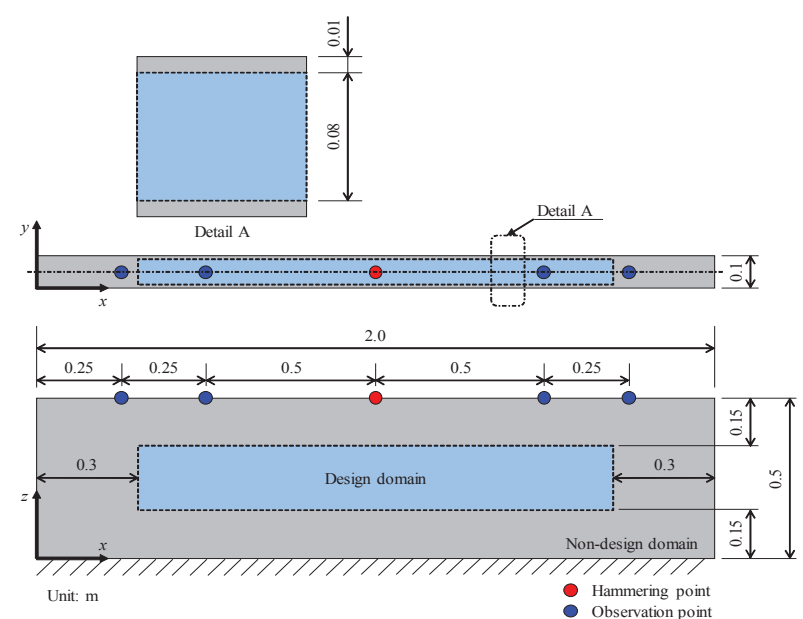

Fig. 11 Boundary conditions. 


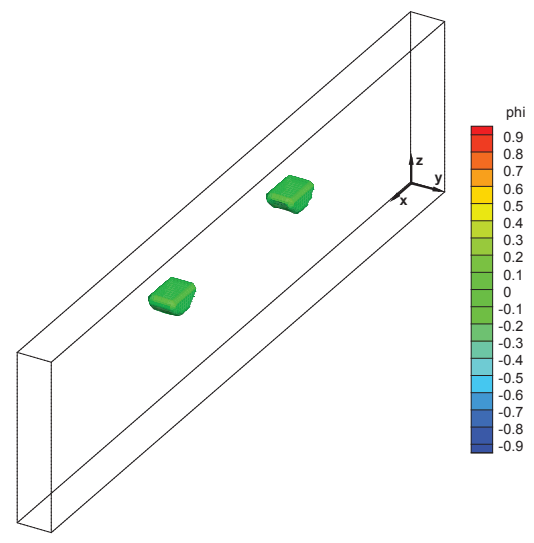

Fig. 12 Identified result at the final iteration.

Fig. 12 に同定された空洞領域を示す。同定された空洞 領域の数は目標モデルと同じとなり, 空洞領域が左右に 分裂して目標モデルよりも打撃点寄りに空洞領域が存在 する結果が得られた。 これは, 解析モデル上, 最もたわ みやすい部分を打撃点として設定し, さらに集中力とし て 1 節点に打撃力を与えたためであると考えられる。ま た，同定後の空洞領域は目標モデルより $68.2 \%$ 小さくな り，下面が丸くなる結果が得られた。この結果は正則化 パラメータ $\tau$ に起因するものであり, 界面拡散効果によ り下面が丸く同定されたものと考えられる.形状の同定 精度は, 構造の破壊の評価時に影響するため, さらなる 同定精度の向上は今後の課題である. Fig. 13 に評価関数

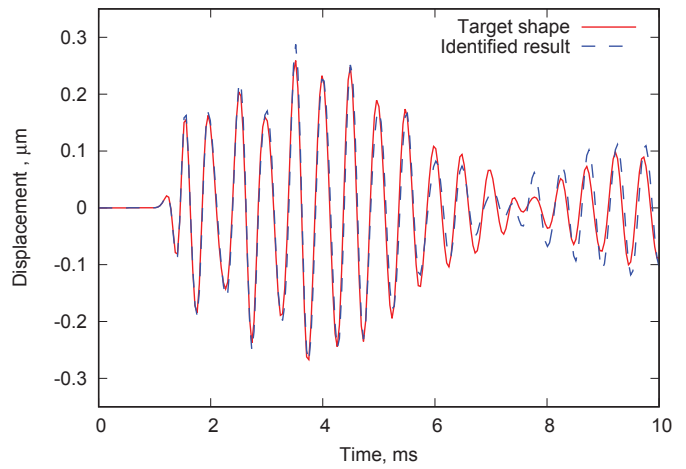

Observation point $\mathrm{P} 1$.

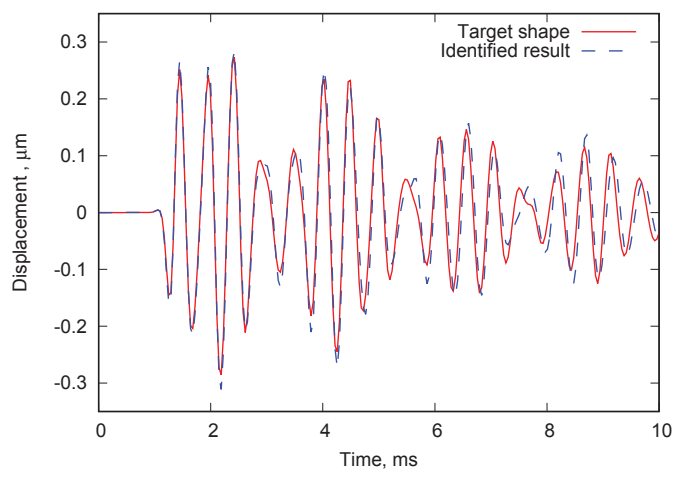

Observation point $\mathrm{P} 3$.

Fig. 14 Comparison between the target displacement and the identified displacement.

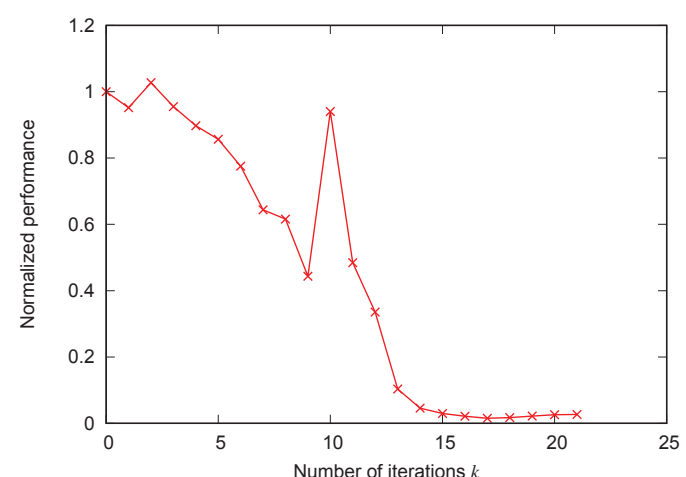

Fig. 13 Convergence history of the performance function.

の収束履歴を示す. 図より, 評価関数に数值振動が見ら れるが, 評価関数の值は初期よりも大幅に減少している ことがわかる

Fig. 14 に各観測点 P1 P4 における目標モデルの変位 波形と同定後の変位波形を示す。同定後の変位波形は, 目標モデルの変位波形と良好に一致していることが確認 できる。また, 観測点 P1, P3 および観測点 P2, P4 の組 では, 同一な変位波形が得られていることから, 同定計 算過程で対称性が担保されていることがわかる. 解析対 象モデルに対し, 打撃点や観測点を非対称に配置した場 合や, 適切な観測点の数の設定については, 実用の観点 から今後の検討課題とする.

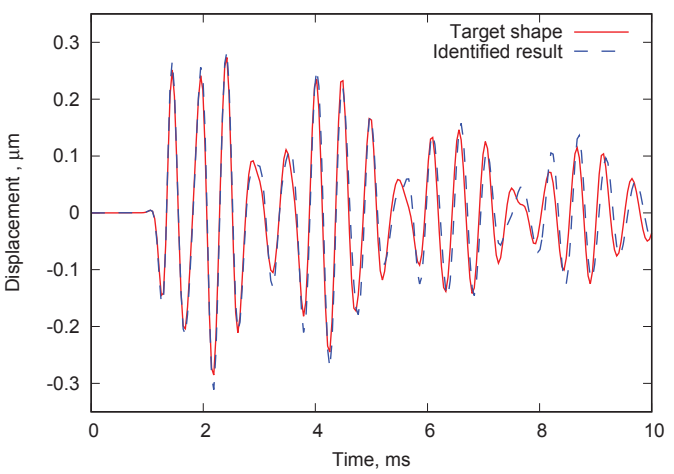

Observation point P2.

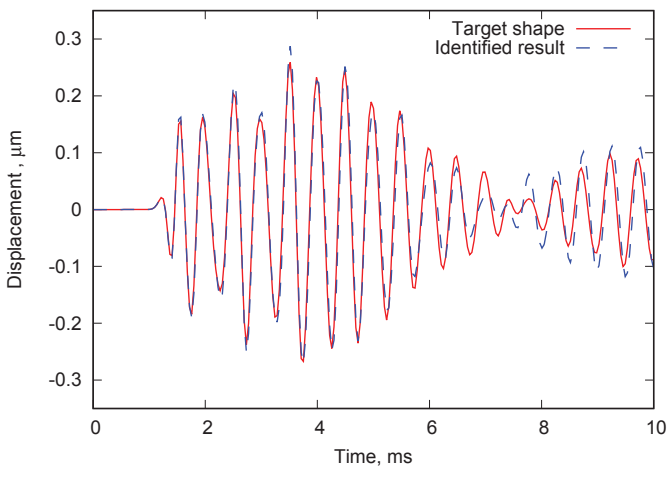

Observation point P4. 
6 結論

本論文では、フェーズフィールド法の考え方を用いた レベルセット型トポロジー最適化に基づいて, 打撃試験 による空洞領域の可視化について試みた。数值実験結果 により, 以下の知見が得られた。

(1) 本手法は, 空洞形状まで一致させることは難しいも のの, 正則化パラメータ $\tau$ の設定により, 空洞領域の数 や位置を適切に同定できる。

(2) 適切な正則化パラメータ $\tau$ の值は問題設定に依存す るため，いくつか $\tau$ を設定し，評価関数の収束值に基づ いて最適な空洞領域を見出す必要がある。

計算コストの面では，2 次元モデルの方が容易に検討 は実施できるが, 破壊の評価も含めた実用面から考える と, 3 次元モデルの方が好ましい. 3 次元モデルによる き裂の進展の解析に関する研究 ${ }^{13)}$ も行われており, 作 用する荷重によっては，3 次元的にき裂が進展していく ことも報告されている ${ }^{14)}$ 。このような観点から，3 次元 モデルに対する空洞領域の可視化において, 空洞形状の 同定精度をより向上させる必要があると考えている。

本研究の遂行にあたり，新潟県建設技術センター「微 弱打撃により取得した加速度応答データを援用した検査 場所非依存型の空洞位置同定解析手法の構築に関する事 業」に関する経費ならびに長岡技術科学大学学長戦略的 経費による援助を受けた。また，数值実験には九州大学 情報基盤研究開発センターの高性能演算サーバーシステ ムを利用した。記して謝意を表す。

\section{参 考 文 献}

1) T. Kamada, M. Asano, M. Kunieda and K. Rokugo, "Application of hammering method to quantitative non-destructive inspection of a surface defect of a concrete structure", Journal of Japan Society of Civil Engineering, Vol.2002, No.704, pp.65-79 (2002).

2) Y. Sonoda, K. Kawabata, M.Beppu and Y. Fukui, "A fundamental study on the evaluation method of inner defect of concrete using hammering test data", Journal of Structural Engineering, Vol.57, Part A, pp.802811 (2011).

3) S. Lee, T. Kamada, S. Uchida and D. Linzel, "Imaging defects in concrete structures using accumulated SIBIE", Construction and Building Materials, Vol.67, Part B, pp.180-185 (2014).

4) A. Nouchi, Y. Murakami, T. Iyama and S. Toyama, "Evaluation of defective areas inside concrete structures through application of frequency response function data to Self-Organizing Map", Concrete Research and Technology, Vol.29, No.29, pp.87-100 (2018).

5) M.P. Bendsøe and O. Sigmund, "Topology Optimization Theory, Methods and Applications", Springer, (2003).

6) S. Osher and R. Fedkiw, "Level set methods and dynamic implicit surface", Springer, (2003).

7) J. Sokolowski and A. Zochowski, "On the topological derivatives in shape optimization", SIAM Journal on Control and Optimization, Vol.37, Issue 4, pp.12511272 (1999).

8) K. Matsushima, H. Isakari, T. Takahashi and T. Matsumoto, "An application of topology optimization to defect identification in two-dimensional elastodynamics with the BEM and H-matrix method", International Journal of Computational Methods and Experimental Measurements, Vol.6, Issue 6, pp.1033-1042 (2018).

9) S. Nishiwaki, K. Izui and N. Kikuchi, "Topology optimization", Maruzen, (2013).

10) T. Yamada, S. Nishiwaki, K. Izui, M. Yoshimura and A. Takezawa, "A Structural optimization method incorporating level set boundary expressions based on the concept of the phase field method", Transaction of Japan Society of Mechanical Engineering, Series A, Vol.75, No.753, pp.550-558 (2009).

11) N. Provatas and K. Elder, "Phase-field methods in materials science and engineering", Wiley- $\mathrm{VCH}$, (2010).

12) A.N. Tikhonov and V.Y. Arenin, "Solution of Illposed Problem", John Wiley \& Sons (1977).

13) T. Tokuda, H.Kawai, H. Okada and Y. Fukui, "Development of automated crack propagation analysis system (1st report, outline of the system and finite element model generation)", Transaction of Japan Society of Mechanical Engineering, Series A, Vol.76, No.770, pp.1255-1262 (2010).

14) H. Okada, H. Kawai, T. Tokuda and Y. Fukui, "Development of automated crack propagation analysis system (2nd report, the crack propagation analysis system and finite element model generation for the crack propagation)", Transaction of Japan Society of Mechanical Engineering, Series A, Vol.76, No.772, pp.1681-1688 (2010). 